\title{
Strategies to combat man-animal conflicts
}

\begin{abstract}
Over a period of time, Human Population pressure has resulted in conversion of forest wildlife habitat into tea estates, tea factories and change in the land use is visualized. This is evident in reduction of dense forest area where more number of wild lives has their food, shelter, breeding and water requirements. There were so many streams, pools, source of river and tributaries. Currently they were extinct from the scene and animals for want of food, water and other requirements started migrating to the farm environment or near to the water hole. During these journeys, human and the animal conflicts become visualized resulted in more number of deaths and injuries. On an average, every year two human deaths and many injuries are occurring. For that the forest department has paid 123 lakhs of Rupees as compensation for affected victims. The affected individuals are migrated personnel to the forest floor for employment and other purposes. Whereas, the tribes were not affected. The main reason is the people migrate to forest floor are not aware on the animal behavior, movement and hence awareness creation exercise found to be the principal strategy to the human to avoid the conflicts.
\end{abstract}

Keywords: human-animal conflicts, strategies, forest conservation, livestock, mount hunting parties
Volume 2 Issue 3 - 2018

\author{
Sekhar C,' Vidhyavathi A,' Baranidharan K² \\ 'Department of Agricultural Economics, Tamil Nadu Agricultural \\ University, India \\ ${ }^{2}$ Department of Forestry, Forest College and Research Institute, \\ India \\ Correspondence: Sekhar C, Professor, Department of \\ Agricultural Economics, Tamil Nadu Agricultural University, \\ Coimbatore, 64I 003, India, Email saekarck@gmail.com
}

Received: March 08, 2018| Published: May 02, 2018

\section{Introduction}

The United States Geological Agency defines human-wildlife conflict in two contexts; firstly, actions by wildlife conflict with human goals, i.e. life, livelihood and life-style, and, secondly, human activities threaten the safety and survival of wildlife. However, in both cases, outcomes are decided by human responses to the interactions. ${ }^{1}$ The advent of farming practices including animal husbandry of the Neolithic Revolution increased the scope of conflict between humans and animals. The crops and the produce formed an abundant and easily obtained food source for wild animals. Wild herbivores competed with domesticated ones for food and fodder. In addition, they were a source of diseases which affected livestock and livestock rearing practices in Toto. The livestock attracted predators which found them an easy source to prey on. The inevitable human reaction was to eliminate such threats to agriculture and domesticated animals. In addition, land was converted to agricultural and other uses by destroying forest land, all of which impacted wild animals adversely. The grazing lands in the wilder zone were also brought to damage for crop cultivation and other requirements. A number of animal species were eliminated locally or from parts of their wild range due to absence of living conditions to the animals. The deliberate or accidental introduction of animals in isolated island animal communities has caused extinction of a large number of species.

\section{Nature of man-animal conflicts}

As human populations expand into wild animal habitats, natural wildlife territory is displaced. Reduction in the availability of natural prey/food sources leads to wild animals seeking alternate sources. Alternately, new resources created by humans draw wildlife resulting in conflict. The population density of wildlife and humans increase with overlaps in geographical areas used increasing their interaction thus resulting in increased physical conflict. Byproducts of human existence offer un-natural opportunity for wildlife in the form of food and sheltered interference and potentially destructive threat for both man and animals. Competition for food resources also occurs when humans attempt to harvest natural resources such as fish and grassland pasture. Another cause of conflict comes from conservation biased toward flagship or game species that often threatens other species of concern (Wikipedia).

\section{The outcomes of conflicts}

Human-wildlife conflict occurs with various negative results. The major outcomes of human-wildlife conflict are: ${ }^{2}$

a. Injury and loss of life of humans and wildlife

b. Crop damage, livestock depredation, predation of managed wildlife stock.

c. Damage to human property.

d. Trophic cascades.

e. Destruction of habitat.

f. Collapse of wildlife populations and reduction of geographic ranges

\section{The problem focus}

A deadly conflict is underway between India's growing masses and its wildlife, confined to ever-shrinking forests and grasslands, with data showing that about one person has been killed every day for the past three years by roaming tigers or rampaging elephants. Statistics released by the environment ministry count a total of 1,144 people killed between April 2014 and May 2014.That includes 426 human deaths in fiscal 2014-15, and 446 killed the following year. The Ministry released only a partial count for 2016-17 of 259 killed by elephants up to February 2017, along with 27 killed by tigers through May. "Conflict is already one of the biggest conservation challenges," said Belinda Wright, founder of the Wildlife Protection Society of India, based in New Delhi. "In India it is particularly acute 
because of the high human population." That population of 1.3 billion is still growing, and as it does it is increasingly encroaching into the country's traditional wild spaces and animal sanctuaries, where people compete with wildlife for food, fodder, fuel and other resources. The growth of human settlements is often seen as economic development. But for some who are living on the edge of wildlife borders, this development can come at a high cost. Of the 1,052 lives claimed by the elephants in the last three years, many had simply been in the way when the pachyderms wandered out of jungles in search of vegetation and raided farmers' crops. Wildlife experts say these conflicts have increased as elephants increasingly find their usual corridors blocked by highways, railway tracks and factories. ${ }^{3}$

"The shrinking of good quality habitats and access of the animals to movement corridors are absolutely critical for India's conservation efforts and the future of its iconic mammals. The human conflict with tigers has gradually increased since the 1970s, when India launched a nationwide tiger conservation program that carved out sanctuaries in national parks and made it a crime to kill a big cat. Though methods for counting tigers have changed, census evidence suggests the number has increased from about 1,800 then to 2,226 in 2014. But the increase in tigers hasn't been met with a proportional increase in habitat, activist's say. ${ }^{3}$ While the government did not provide any numbers for deaths caused by other big cats, conflicts with leopards have become so common that villagers regularly mount hunting parties when one ventures near their homes, threatening children and livestock. India's elephants and tigers are also some of the most hunted animals in the country, sought for their ivory tusks or bones that are sold on the black market for use in traditional Chinese medicine without any evidence that they have an effect. Elephants are also threatened by speedy trains and three elephants were killed due to the speedy train near Madukkarai of Coimbatore, Coimbatore District, Tamil Nadu. Like that several deaths are happening to Human as well as to the Wild Animals. What were the reasons to face with such conflicts between the human and the wild animals? Still many of them could not answer to the emerging problem and hence the author has made a small attempt to understand the Tiger Reserve and attempted to highlight the nature of forests in the Reserve, Facilities provided to the wild animals for keeping them in their wilder environment, factors facilitating the human animal conflicts in the reserve, schemes in vogue to protect the animals and the human friendly living and to suggest the appropriate strategies to augment the animals in the wilder zone.

\section{Design of the study}

Methodology refers to the blueprint or set of decisions and procedures which governs a study and makes it understandable to others. It is also subject to inquiry, criticism, replication and adaptation to other settings. ${ }^{4}$ The research methodology is an approach used to justify the methods adopted for research leading to creation of data for analysis of research under consideration. ${ }^{5}$ The types of research Methodologiesavailable are quantitative and qualitative. ${ }^{6}$

\section{Quantitative methodology}

The quantitative methodology is used where the number of respondents is more and the data can be effectively measured using quantitative techniques such as Statistical Package for the Social Sciences (SPSS). ${ }^{7}$

\section{Qualitative methodology}

The aim of the methodology is to examine the interpretation of the reality from the respondents'view point. ${ }^{8}$ The effective means of creating a framework where the respondent is to provide response to the interviews or texts and the response to the interviews can be open.

\section{Research strategy}

The research strategy is the technique adopted by the researcher to perform the study on the topic of interest. ${ }^{9}$ There are various steps involved in strategizing a research which might include identifying the scientific problem, the experimental design, data types, methods and experimental techniques (Benestad and Laake, 2015). Saunders et al., ${ }^{9}$ identified different approaches such as case study research, experimental research, interviews, action research, literature reviews and surveys. The current research is concentrated on the procurement practices of SPAR hypermarket which translates to adopt case study as the research strategy. It is the assessment of single unit which establishes the key features and generalizations of the case in consideration. ${ }^{8}$ It also provides in-sight about the specific nature of culture or context in comparison to other cases.

\section{Data analysis}

In the current research, the interview method is adopted, as the qualitative methodology is based on the inductive approach, the patterns are derived from the data as a preconditioning for the study. ${ }^{7}$ The interview data is grouped accordingly to the common factors exhibited by the respondents, the results of the research are established based on the data examined and its best fit with the current framework of research design. ${ }^{10,11}$ The interview strategy in the researches are conducted in the area of social sciences. ${ }^{8}$ Considering the importance of protecting the wild animals and to identify the reasons for human animal conflicts in the wilder zone or in the forest fringes, a Case Study approach has been practiced in the Anamalai Tiger Reserve of Tamil Nadu. For that Case Study, the Field Director of Anamalai Tiger Reserve and the staff members at different levels were discussed for want of first-hand information on Human-Animal Conflicts. Besides, the secondary data available with the Tiger Reserve were also collected from the records of Tiger Reserve and analyzed using conventional percentage analysis. Though there were six ranges in the Tiger Reserve, the author could not perform a field visit to all the ranges but have visited only the Anamalai Tiger Reserve located in the Pollachi and Ulandy Range were alone performed and the interactions were made with the protection officials of the ranges. In addition to this, the wild life experts, the field personnel in the Wild life Protection Society, the Scientists whom are dealing the issues are also discussed and their experiences were taken note off to document the results in an appropriate manner (Table 1).

\section{The sample size}

The sample size is a representation of number of participants selected from the overall data set which are used in the research. In quantitative research, the sample size is most fundamental as the precision of the outcomes are directly linked with the sample size. For instance, the sample size less than 50, tends to produce results of lower accuracy as the results are dependent on the people providing data. The people who provide data tend to skew the results, hence it is suggestive to have larger sample size thus producing more reliable and accurate results. ${ }^{12}$ 
In qualitative research methodology, the sample size is less important and has a sample size from 15 to 30 (Moen and Middelthon, 2015) which is found sufficient since the qualitative survey has been conducted with the experts of Wild Life of Anamalai Tiger Reserve, especially the Field Director, Mr. V. Ganesan belonged to the Indian Forest Service of Tamil Nadu Cadre had 35 years of rich experience in the forests capable of manning the in-and-outs of the ManAnimal Conflicts. The data related to the factors and suggestions for mitigating the conflicts are of exclusive thoughts of Mr. V. Ganesan, the Field Director of the Tiger Reserve who is enforcing the same in the Tiger Reserve to control the conflicts between the human and the animals. Amidst his excellence, the other personnel have also been discussed for their opinion and the details of personnel are delineated in Table 1. Their excerpts formed the backbone for detailed analysis of the research work and the details are discussed in the Results and Discussion section.

Table I Details of experts considered and selected for conducting the study

\begin{tabular}{lll}
\hline SI. No & Details of Contact Person & Number of Contacts \\
\hline I & Field Director of ATR & I \\
2 & Biologist of ATR & I \\
3 & Forest Range Officers & 2 \\
4 & The Wild Life Scientists & 3 \\
5 & Field Personnel & 2 \\
6 & $\begin{array}{l}\text { Common Public } \\
\text { Total Number of Contacts } \\
\text { Made }\end{array}$ & 6 \\
\hline
\end{tabular}

\section{Period of study}

The study was carried out in the Anamalai Tiger Reserve, Pollachi between November 2017 and January 2018. Besides, the data collected during the Wild Life Census 2017 were also used for the study for drawing appropriate strategies to combat the man-animal conflicts.

\section{Results and discussion}

The study has focused mainly on how to combat the man-animal conflicts and what are the principal strategies which are needed to combat the conflicts. If not fully, how to minimize the conflicts in the forest jungle is discussed in the following headings:

a. Forest Cover in India

b. Details of Tiger Population in India

c. Details of Man-Animal Conflicts held in a Decade of Time

d. Strategies Needed for Combating the Conflicts

\section{Forest cover of India and Tamil Nadu}

A country's prosperity lies with its vast natural resources especially the Forest and other resources like water, land for agricultural and allied activities. Higher percentage of forest cover would naturally augment higher biodiversity, capable of attracting rain forming clouds, protects streams and ensure filling of ponds and tanks which in turn promotes agriculture and allied sectoral development. Hence a growing nation will always keen on developing the forests and its biodiversity richness. Since this study focuses on factors influencing the human animal conflicts, one has to assess the reasons and causative factors in particular. The author considers area under forests is one of the influencing factor and hence the details of forest cover is analyzed and the results are presented in Table 2. The total geographical area of the country is 329 square kilometers. Out of which the forest cover is accounted for only 21.54 per cent indicating that the country is devoid of forest cover to the tune of 12 per cent to meet the recommended forest cover of 33 per cent to the total geographical area. Hence, the nation like India has to make hard efforts to bring the higher area under forests focusing the trees outside forest environment besides protecting the existing forests. If forests are left undisturbed for certain period of time like ten years or more, the natural regeneration could enrich the forest cover and the open forest becomes moderately dense and the moderately dense becomes dense forests and the dense forests become the shola forests where one could expect higher biodiversity.

Table 2 Forest cover of India

\begin{tabular}{ccc}
\hline Class of Forests & Area in Sq. Kms & $\begin{array}{c}\text { Percentage to } \\
\text { Geographical } \\
\text { Area }\end{array}$ \\
\hline Very Dense Forests & 98158 & 2.99 \\
Moderately Dense Forests & 308318 & 9.38 \\
Open Forests & 301797 & 9.18 \\
Total Forest Cover & 708273 & 21.54 \\
Scrub Jungle & 45979 & 1.4 \\
Non Forest Areas & 2533217 & 77.06 \\
Total Geographical Area & 3287469 & 100 \\
Forest Cover of Tamil Nadu & \\
Very Dense Forests & 3672 & 2.83 \\
Moderately Dense Forests & 10979 & 8.44 \\
Open Forest Areas & 11630 & 8.94 \\
Total Forest Cover & 26281 & 20.21 \\
Non Forest Areas & 103779 & 79.79 \\
Total Geographical Area & 130060 &
\end{tabular}

The Scrub Jungle is accounted for around 1.40 per cent. These scrub jungle should be elevated as fodder bank without disturbing the natural vegetation so that the dominance of herbivores and its migration to farm fields in the boundaries could be checked. When comparing the forest cover at national level and the forest cover in the state of Tamil Nadu, Tamil Nadu forest cover is almost equal to the national forest cover. The nation's forest cover is marginally ahead when comparing the figures of Tamil Nadu and hence green budgeting should be brought in by both central and state governments and forest accounting should be taken care on an annual basis or once in two years. The disturbance due to the growth of Prosopis juliflora in the forest fringes and in the open forests is the big impediment to the conservation related activities and hence the growth of Prosopis should be checked on an annual basis to permit the growth of fodder trees to the herbivores. In an effort by the Gudalur Forest Division, Ooty, a forewarning system near to a school was made to inform the residents about the movement of elephants in the area as the school is nearby the elephant corridor. According to the Forest Range Officer of Bitherkad range, the school has an alarm and lights that would go on when animals cross the sensor attached to it. It will make people to take precautionary measures accordingly. ${ }^{13}$ This effort has been taken by the District Forest Officer of Gudalur Division as the elephants 
used to cross regularly and hence the forewarning system will be of much useful.

\section{Schemes for conservation of wild life population in India}

There were so many schemes promoted by Ministry of Environment, Forests and Climate Change of Government of India, New Delhi. Among the Schemes, the following are most important in the context of conservation of endangered animals in the forests.

\section{Project tiger}

Project Tiger is a scheme centrally sponsored by the Ministry of Environment, Forest and Climate Change. This scheme covers around 47 tiger reserves located across more than 17 regions populated with tigers (Table 3). Project Tiger mainly focuses on conducting assessments of number of tigers, their habitat, hunting habits, etc. All these activities are sanctioned by the Tiger Task Force. For the estimation of Tigers, the Tiger Task Force or the Team engaged in assessing the census of Tigers, the total area covered for the estimation survey is $378 \mathrm{Sq}$. KMs. In that area, the individual Tiger is photographed numbering to the level of 1540 and the number of beats covered for estimating the population of Tiger is 29717 beats of forest area. Table 3 revealed that The Western Ghats, Central India and Eastern Ghats followed by Shiwalik-Gangetic Landscape had the highest Tiger population in India. Among these three the Western Ghats had the top most population of Tigers. The population is estimated to be 778 Tigers in the Western Ghats which is an increase of 46 per cent when comparing to the population of Tigers during the year 2010. Eastern Ghats had the next highest population of Tigers which had 688 numbers during the year 2014. When we compare the same during the year 2010, the population of Tiger is only 601 in numbers which is an increase of only 14.50 per cent during the year 2014. Whereas, the Shiwalik-Gangetic landscape had witnessed an increase of only 37 per cent of Tiger population during the year 2014 over the year 2010. When one could compare the overall increase of Tiger population during the year 2014 over the year 2010, the increase is accounted for only 30 per cent in India. Among the States, the percentage increase of Tigers population is in favor of Kerala which stands at 90 per cent increase over the year 2010. Whereas, Tamil Nadu has witnessed only a 40 per cent increase in its population during the year 2014 over the year 2010. In general, the increase in Tiger population is visible. It is because of the Project Tiger scheme is in operation with Forest Departments of different States of India.

\section{Project elephant}

Similar to the Project Tiger, the Project Elephant is also initiated by the Government of India in 1992 as a centrally sponsored scheme, the main objective of Project Elephant is to conserve elephants, their habitat, work for issues such as human-elephant conflict and look after the welfare of domestic elephants.

\section{Crocodile conservation project}

This Project was launched in 1976 with the main objective of protecting the three most endangered species of crocodile: the fresh water crocodile, gharials and salt water crocodiles. The Crocodile Conservation Project undertakes captive breeding of various species of crocodiles, looks after the hatching and rearing of gharials in order to decrease the mortality rate of crocodiles. Under Gharial Rehabilitation Project, about 200 gharials were sheltered and consequently released in the Ramganga River in Corbett National Park.

Table 3 State wise and landscape wise estimation of tigers

\begin{tabular}{|c|c|c|c|}
\hline \multirow[t]{2}{*}{ Particulars of State / Landscape } & \multirow[t]{2}{*}{$\begin{array}{l}\text { Percentage } \\
\text { Change during } \\
2014 \text { over } 2010\end{array}$} & \multicolumn{2}{|c|}{$\begin{array}{l}\text { Tiger Population } \\
\text { in Numbers }\end{array}$} \\
\hline & & 2010 & 2014 \\
\hline Shiwalik- Gangetic Landscape & 37.39 & 353 & 485 \\
\hline Uttarakhand & 49.78 & 227 & 340 \\
\hline Utter Pradesh & $(-) 00.85$ & 118 & 117 \\
\hline Bihar & 250 & 8 & 28 \\
\hline Central Indian and Eastern Ghats & 14.48 & 601 & 688 \\
\hline Andhra Pradesh & $(-) 06.85$ & 73 & 68 \\
\hline Chhattisgarh & 76.92 & 26 & 46 \\
\hline Madhya Pradesh & 19.84 & 257 & 308 \\
\hline Maharashtra & 12.43 & 169 & 190 \\
\hline Odisha & $(-) 12.50$ & 32 & 28 \\
\hline Rajasthan & 25 & 36 & 45 \\
\hline Jharkhand & $(-) 70.00$ & 10 & 3 \\
\hline Western Ghats & 45.69 & 534 & 778 \\
\hline Karnataka & 35.33 & 300 & 406 \\
\hline Kerala & 91.55 & 71 & 136 \\
\hline Tamil Nadu & 40.49 & 163 & 229 \\
\hline Goa & 0 & 0 & 5 \\
\hline North Eastern Landscape & 8.57 & 70 & 76 \\
\hline Assam & 16.78 & 143 & 167 \\
\hline Arunachal Pradesh & 0 & 0 & 28 \\
\hline Mizoram & (-) 40.00 & 5 & 3 \\
\hline West Bengal & 0 & 0 & 3 \\
\hline Brahmaputra Region & 35.81 & 148 & 201 \\
\hline Sundarbans & 8.57 & 70 & 76 \\
\hline Total Estimated Tigers & 29.73 & 1776 & 2304 \\
\hline \multicolumn{2}{|l|}{ Area Covered for Wildlife Census } & \multicolumn{2}{|c|}{ 378.118 Sq. KMs } \\
\hline \multicolumn{2}{|c|}{ Number of Individual Tigers Photographed } & \multicolumn{2}{|l|}{1540} \\
\hline Number of Sample Beats & & 29717 & \\
\hline
\end{tabular}

(Source: Ministry of Environment, Forests and Climate Change Web Site)

\section{GOI-UNDP sea turtle project}

Executed by Ministry of Environment along with Wildlife Institute of India, Dehradun, The Government of India- UNDP Sea Turtle Project works to protect sea turtles. Launched in 1999, this project carries out rigorous surveys along the coastal areas, checks 
the community and legal conservation, creates awareness, gathers information about main nesting areas and also provides training to fisheries managers, researchers and biologists.

\section{Vulture conservation project}

Because of a serious decline in the population of the main species of vulture, a series of meetings and seminars are being held in India in order to address the need for vulture conservation. The National Workshop held in New Delhi in 2004, for the same cause was attended by Chief Wildlife Wardens, BNHS (Bombay Natural History Society), SACON (Salim Ali Centre for Ornithology and Natural History, Coimbatore), GEER (Gujarat Ecological and Education Research Foundation, Gandhinagar), and Department of Animal Husbandry of different states. All States have been advised to set up State level Committees to continuously monitor the vulture population and conservation efforts. These State level committees would periodically report to the National Level Vulture Conservation Advisory and Steering Committee. A set up exists informally, but it is proposed to set up a formal multi agency national committee with a mandate for working out strategies for vulture conservation by identifying priority areas for focus for the future.

\section{Indian rhino vision 2020}

India Rhino Vision (IRV) 2020 is an effort of pact made by the Bodoland Territorial Council, WWF (World Wildlife Fund), IRF (International Rhino Fund) and the US Fish and Wildlife Service. The main objective of IRV is to conserve at least 3000 greater one-horned rhinos in Assam, India by 2020.

\section{Details of man-animal conflicts held in a decade of time}

Besides conservation of many endangered species of wild life, the man-animal conflicts are also taking place either inside the jungle or in the forest fringes for want of food, fodder, water and breeding requirements of animals. Similarly, because of high growth of population of human being, he also migrates, encroach the forest floor and invade the forest for hunting, search of food, search of fodder for farm animals and other purposes. During the search both are happened to meet incidentally and the conflict took place. These conflicts held over the period of ten years is analyzed and presented in Table 4. When one could examine the human-animal conflicts in a decade of time, the human death seems to be 22 in numbers with an average of 2 deaths per annum due to the elephants. In respect of panther attack, on an average, one human being is affected to death and the death of one human due to Gaur happened every two year. On examining the stream of death of human over the years, it is found to be an incidental death. The incidental death is mainly due to the carelessness of human folk inside the Tiger Reserve. If one could take precautionary efforts, the deaths could have been avoided and the reserve could be a pleasant one to them on following the instructions of the Tiger Reserve officials or the fore-warning given by the tribes and other authorities in the reserve. The compensation paid for the death and lifting of cattle was arrived at Rs 123 lakhs. Such conflicts are to be avoided or minimized by establishing some infrastructure and framing certain policies for effective implementation and monitoring also by the higher officials periodically is warranted. However, the details of strategies which are needed are highlighted for the perusal of policy makers and the implementing authorities.

Table 4 Details of human-animal conflicts over the years in the tiger reserve of Tamil Nadu

\begin{tabular}{|c|c|c|c|c|c|c|c|c|c|}
\hline \multirow{2}{*}{ Sl. No } & \multirow{2}{*}{ Year } & \multicolumn{2}{|c|}{$\begin{array}{l}\text { Man - Elephant } \\
\text { Conflicts }\end{array}$} & \multicolumn{2}{|c|}{$\begin{array}{l}\text { Man-Panther } \\
\text { Conflicts }\end{array}$} & \multicolumn{2}{|c|}{ Man-Gaur Conflicts } & \multicolumn{2}{|c|}{ Other Conflicts } \\
\hline & & Death & Injury & Death & Injury & Death & Injury & Death & Injury \\
\hline 1 & 2007-08 & 2 & 2 & 1 & 1 & 0 & 0 & 0 & 0 \\
\hline 2 & 2008-09 & 1 & 0 & 1 & 2 & 2 & 0 & 0 & 0 \\
\hline 3 & $2009-10$ & 1 & 0 & 0 & 0 & 0 & 0 & 0 & 0 \\
\hline 4 & 2010-11 & 4 & 0 & 2 & 2 & 0 & 0 & 0 & 0 \\
\hline 5 & 2011-12 & 2 & 4 & 2 & 1 & 0 & 1 & 0 & 5 \\
\hline 6 & $2012-13$ & 2 & 2 & 1 & 1 & 2 & 2 & 1 & 4 \\
\hline 7 & 2013-14 & 0 & 2 & 0 & 1 & 0 & 1 & 1 & 3 \\
\hline 8 & 2014-15 & 2 & 1 & 0 & 2 & 1 & 2 & 0 & 5 \\
\hline 9 & $2015-16$ & 3 & 1 & 0 & 0 & 1 & 3 & 0 & 11 \\
\hline 10 & $2016-17$ & 0 & 0 & 0 & 0 & 0 & 0 & 0 & 5 \\
\hline 11 & $2017-18$ & 5 & 2 & 1 & 0 & 0 & 3 & 1 & 6 \\
\hline \multicolumn{2}{|r|}{ Total } & 22 & 14 & 8 & 10 & 6 & 12 & 3 & 39 \\
\hline \multicolumn{2}{|r|}{ Mean } & 2 & 1.27 & 0.73 & 0.91 & 0.55 & 1.09 & 0.27 & 3.55 \\
\hline
\end{tabular}

\section{Strategies to combat man-animal conflicts}

There were many strategies which are implemented on trial and error basis to combat the man animal conflicts. Few are successful for some time and the animals after some time learned to violate the measures taken by the human being. Hence, revisiting of strategies are needed to often to combat the conflicts. Table 5 has prescribed few of such strategies erected or to be erected in the ATR for the peaceful living of animals and the human being. In Table 5, erection of street lights in the residential as well as estate roads become more important and the clearing of sides of the roads to the width of 10 meters at least to avoid hiding of animals for attack on human being. In this respect, clearing of Tea bushes along the road and the estate roads becomes important. Taking the staff members to the tea industries or 
to the estates for employment in a closed vehicle so that the attack by the carnivores could be minimized. In addition to this, provision of insurance cover to the employees are also vital that should be provided by the tea estates and tea factories under group insurance program for life saving. Currently, the stationary ration shop contains food materials which are ransacked by the elephants for its food and other requirements and hence the revenue officials should revisit the establishment of ration shop in the form of a mobile one to cater the needs of poor households in the ATR so that the damage of ration shop could be minimized.

Table 5 Strategies to combat man-animal conflicts in the wilder zone of ATR

\begin{tabular}{ll}
\hline Sl. No & Strategies Needed \\
\hline 1 & Erection of Elephant Proof Trench in the forest fringes \\
2 & Erection of Bio- Walls using Honey bees \\
3 & Erection of Street Lights in the Residential and Estate Roads \\
4 & Establishment of Mobile Ration Shops and their Feasibility \\
5 & Clearing of Bushes and Tea Plants in Ten Meter Radius along the Residential Areas and Roads \\
6 & Provision of Life Insurance Cover to the Employees by the Industries / Tea Estates \\
7 & Provision of Closed Vehicle Facility to the Wards of Employees of Tea Estates \\
8 & Safe Disposal of Remains of Meat Shops to avoid Carnivores \\
9 & Rearing of Animals like Goats, Dogs, Cats, Poultry should be avoided \\
10 & Rearing of Milch Animals should be in an Iron Fence with a way to move from inside the house \\
11 & Playing of Children in an unprotected environment should be avoided \\
12 & $\begin{array}{l}\text { Cultivation of Banana Trees in the Residential Environment will attract Elephants and hence the same } \\
\text { may be avoided }\end{array}$
\end{tabular}

\section{Improvement of habitat}

It is duty of Ministry of Environment \& Forest to provide assistance to State Governments for improvement of habitat to augment food and water availability and to minimize the animal movement from the forests to the habitations.

\section{Training programs}

To address the problems of human- wildlife conflict it is essential to train the police offices and local people. It is duty of forest department to frame the guidelines for management of human-leopard conflict and publish the same in the local community.

\section{Awareness programs}

To sensitize the people about the Do's and Don'ts to minimize conflicts is necessary to make aware of the local people. The Trainers should be from Forest Wildlife Officials, The leading Tribes and their representative who could deliver the animal movement, animal corridor, animal behavior during the feeding season, breeding season and their behavior during the presence of their kids and how the human behavioral change should be to cope with the movement inside the forests are to be delivered as contents.

\section{Technical and financial support}

Providing technical and financial support for development of necessary infrastructure and support facilities for immobilization of problematic animals through tranquilization, their translocation to the rescue centers or release back to the natural habitats.

\section{Boundary walls}

Providing assistance to State Governments for construction of boundary walls and solar fences around the sensitive areas to prevent the wild animal attacks. In certain cases, these have become failure. To be specific, the erection of solar or battery operated electric fence was very easily damaged by the elephants by giving pressure to the poles erected and then the entire fence fell down and the elephant cross away along with their calves for feeding.

\section{Eco-development activities}

Providing assistance to the State Governments for eco-development activities in villages around Protected Areas to elicit cooperation of local community in management of the Protected Areas. Encouraging and supporting involvement of the research and academic institutions and leading voluntary organizations having expertise in managing human -wildlife conflict situations.

\section{Erection of bio walls by save the elephants (STE)}

Save the Elephants (STE) is a UK registered charity based in Kenya founded organization in September 1993 by Lain Douglas Hamilton. Save the Elephants works to sustain elephant populations and preserve the habitats in which elephants are found, while at the same time fostering a heightened appreciation and visibility for elephants and their often fragile existence. The organization uses a four pillar approach to fulfill its mission statement, combining habitat protection, research, grass roots organization and involvement, and through disseminating information through television, films, publications and new media sources. Save the Elephants has been instrumental in helping to revitalize African Elephant populations, while at the same time, increasing awareness in the many issues which threaten to erode elephant populations and the habitats in which they live. Lain Douglas Hamilton has played an integral role in stopping the illegal ivory trade throughout the world, while at the same time raising the profile of elephant conservation and awareness. The research effort of one 
employee of STE named "Lucie E King" has invented Honey bee (Bio) wall to combat the elephants. This has been tested in Kenya and several other places. On seeing the honey bees and their voice, the elephants have avoided the particular route to browse the farm fields. In India, this has been tested in Karnataka (Canara District) and Kerala (Vayanadu District) by erecting honey bee fence and found that the honey bee fence is very effective,${ }^{13}$ and hence Tamil Nadu can also explore the successfulness of Honey Bee Fence erected in Kerala and Karnataka and the same may be transformed to Tamil Nadu for effective protection of Elephants.

\section{Summary}

Manning the man-animal conflicts itself an art. The skilled individual is performing better in such critical situations and some do not. Based on the experiences, some strategy becomes workable and some of the strategies become obsolete as the animal tried to learn to violate over a period of time. Currently, among all the strategies, erection of elephant proof trench and the bio-wall found to be effective and hence the implementing agencies can concentrate on the workable strategies.

\section{Acknowledgements}

None.

\section{Conflict of interest}

Authors declare that there is no conflict of interest.

\section{References}

1. Cline R, Sexton N, Stewart SC. A Human Dimensions Review of HumanWildlife Disturbance: A Literature Review of Impacts, Frameworks and Management (PDF) (Report). US Geological Survey open file report. 2007;88:2007-1111.
2. Woodroffe R, Thirgood S, Rabinowitz A. People and Wildlife Conflict or Co-Existence. Cambridge University Press. 2005.

3. Associated Press, New Delhi. Man-animal conflict: One human dies every day in India. Hindustan Times. 2017.

4. Guthire G. Basic research methods: An entry to social science research. Sage publications. 2010.

5. Carter SM, Little M. Justifying knowledge, justifying method, taking action: epistemologies, methodologies and methods in qualitative research. Qual Health Res. 2007;17(10):1316-1328.

6. Lapan SD, Quartaroli MT, Riemer FJ. Qualitative research: An introduction to methods and designs. $1^{\text {st }}$ ed. Jossy-Bass: San Francisco; 2012.

7. May T. Social research: Issues, methods and process. $4^{\text {th }}$ ed. Open University Press: McGraw Berkshire; 2011.

8. Bryman A. Social Research Methods. $5^{\text {th }}$ ed. Oxford University Press; 2015.

9. Saunders MNK, Lewis P, Thornhill A. Research methods for business students, Pitman: London; 2009.

10. Luo H, Flick UWE. Introducing research methodology: A beginners'guide to doing a research project. JSTOR. 2012.

11. Randall WS, Mello JE. Grounded theory: An inductive method for supply chain research. Int $J$ Physic Distribut Log Management. 2012;42(8/9):863-880.

12. Flick U. Introducing Research Methodology: A beginners' guide to doing a research project. $2^{\text {nd }}$ ed. Sage Publications; 2015.

13. The Hindu. Warning System to Prevent Man-Animal Conflicts. The Hindu Dated. 2018;2. 